\title{
Effect of cruise altitude and alternative aviation fuels on radiative forcing
}

\author{
Tim A. Snijders ${ }^{1}$ and Joris A. Melkert ${ }^{2}$ \\ Delft University of Technology, Delft, 2629 HS, The Netherlands
}

\begin{abstract}
The radiative forcing caused by the emissions of jet aircraft is calculated using data from an aircraft performance model. Data from the performance model is needed to calculate the emissions of the aircraft. The sensitivity function and lifetime of the emitted gasses and particles are used to calculate the integrated radiative forcing of the flight of an aircraft. Analysis of a single flight using different fuels and with different cruising altitudes revealed that contrails and aviation induced cirrus cause the largest integrated radiative forcing. This leads to lowest integrated radiative forcing for a cruise altitude of $6 \mathrm{~km}$ for both Jet A-1 and Hydrotreated Renewable Jet fuel (HRJ). If contrails and cirrus are omitted the best cruise altitude from the calculated set for Jet A-1 is $11 \mathrm{~km}$ while for HRJ $6 \mathrm{~km}$ still leads to the lowest integrated radiative forcing.
\end{abstract}

\section{Introduction}

A IRCRAFT emissions and their effect on radiative forcing form one of the major problems that aviation industry is currently facing. Effort is put into the reduction of fuel consumption and $\mathrm{NO}_{\mathrm{x}}$ emissions. Furthermore, biofuels are considered as a possibility to replace current jet fuel (Jet A or Jet A-1). The use of alternative fuels like biofuels will change the emissions of jet aircraft. These changed emissions may have an influence on the radiative forcing induced by aircraft as well. If this is the case, it is necessary to investigate what the best options are for radiative forcing reduction. The focus of this paper is to investigate these options based on a simplified emissions and radiative forcing model.

The radiative forcing from aircraft emissions is depending not only on the amount of emitted matter but also on the altitude where the emissions take place. This study aims to quantify the effects of aircraft emissions using both conventional and alternative fuels on radiative forcing, with altitude as a variable. The emissions that cause radiative forcing directly or indirectly are calculated throughout the flight. These emissions have a lifetime and sensitivity function that are a function of altitude. The integrated radiative forcing is calculated using the lifetime, sensitivity function and emissions data. The integrated radiative forcing caused by a typical flight with a single-aisle aircraft is analysed for different fuels and variable cruise altitude.

\section{Performance model}

The basis for the determination of the aircraft emissions is formed by an earlier developed aircraft performance model $^{1}$. This model models all flight phases from start to landing. Look-up tables resulting from engine modelling in the Gas Turbine Simulation Program (GSP) are used in a numerical integration of flight performance equations. For the calculation of emissions of a flight, input parameters like payload, range and fuel properties are used. A succession of flight phases is calculated, resulting in output parameters like fuel flow, altitude and airspeed throughout the complete flight. This data is used in the calculation of the emissions.

\section{Emission calculation}

The calculation of the different emissions is done such that no detailed engine data is required. Only flight data from the performance model and from the ICAO emissions databank is being used. More detailed information on pressures and temperatures inside the engine would require look-up tables with more data and very accurate engine models. This would make these calculations much more difficult and less applicable as a simple and effective tool that can be used easily for different aircraft.

${ }^{1}$ PhD student, ASSET, T.A.Snijders@TUDelft.nl, AIAA student member.

${ }^{2}$ Assistant professor, ASSET, J.A.Melkert@TUDelft.nl, AIAA member. 
The estimation of the carbon dioxide $\left(\mathrm{CO}_{2}\right)$ and water $\left(\mathrm{H}_{2} \mathrm{O}\right)$ emissions is done in a rather straightforward way. It is assumed that all carbon in the fuel is used to create $\mathrm{CO}_{2}$. The amount of carbon that is emitted as $\mathrm{CO}$, unburned hydrocarbons and soot is assumed to be very small compared to the $\mathrm{CO}_{2}$ emissions, especially at power settings higher than approach setting. Thus, the hydrogen-to-carbon ratio $(\mathrm{h} / \mathrm{c})$ of a fuel can be used to determine $\mathrm{CO}_{2}$ emissions in combination with the atomic mass of carbon and the molar mass of $\mathrm{CO}_{2}$.

The emissions of water are determined in the same manner. Again it is assumed that the amount of hydrogen in unburned hydrocarbons and soot is negligible compared to that in water. The $\mathrm{h} / \mathrm{c}$ ratio can be applied to determine the emission index of water.

Sulphuric oxide emissions are also dependent on the fuel composition and not so much on engine setting. According to Ref. 2, 50\% of the fuel bound sulphur forms optically active sulphate aerosols. It is assumed that the remaining sulphur leaves the engine in gaseous form as sulphuric oxides. The exact quantity of this gaseous form depends on the type of oxide formed. But since sulphuric oxides have no significant influence on radiative forcing at cruise altitudes of civil jet aircraft ${ }^{2}$, it is not calculated.

Determination of nitrogen oxides $\left(\mathrm{NO}_{\mathrm{x}}\right)$ emissions is more complex. $\mathrm{NO}_{\mathrm{x}}$ emissions are dependent on the temperature in the combustion chamber. Without the use of detailed engine data, a correction must be found that enables the extrapolation from the published emission indices in the ICAO emissions databank to higher altitude and airspeed. The Boeing2 method ${ }^{3}$ uses the ambient pressure and temperature during flight to correct fuel flow to ground level and zero airspeed. The corrected fuel flow is used to find a reference emission index, using linear interpolation between the points in the emissions databank. This reference emissions index is corrected again for ambient pressure, temperature and humidity of the air, which is assumed to be zero at cruise altitude, in order to find the emissions index at altitude and airspeed.

The emissions of soot are hard to quantify. Generally only the Smoke Number is known for an engine and this does not provide an actual number for soot emissions in terms of an Emission Index. Correlation between Smoke Number and soot mass emitted is not clear ${ }^{4}$. When an Emission Index is known for the LTO cycle, the extrapolation to altitude and airspeed requires very detailed engine information, for example the flame temperature ${ }^{4}$. It is outside the scope of this study to analyze the engine details for different fuels and at many altitudes, airspeeds and engine setting. It is therefore decided to use a fixed soot emission index of $0.04 \mathrm{~g} / \mathrm{kg}$ for Jet A- $1^{2}$ and a constant change for other fuels. This will only influence the calculated negative radiative forcing caused by soot, contrails and aircraft induced cirrus are dealt with differently.

\section{Effects of fuel composition}

Alternative aviation fuels have a different composition than Jet A-1. Next to changes in fuel consumption that were determined in the performance calculations, the emission indices change with fuel type as well. For a very exotic alternative fuel like liquid hydrogen the emissions change very clearly; any carbon-containing or sulphurcontaining emissions disappear and only water and $\mathrm{NO}_{\mathrm{x}}$ remain. In the case of synthetic fuels or hydrotreated renewable jet type fuels (HRJ) the changes may be more subtle. Measurements reported in literature show a reduction in soot emissions of 40 to $95 \%^{5-7}$. The reduction reported for cruise setting is around $85 \%$, which will be used in current calculations. The $\mathrm{NO}_{\mathrm{x}}$ emissions decrease between 0 to $5 \%$ according to the same sources. For the current calculations, a reduction in $\mathrm{NO}_{\mathrm{x}}$ emission of $2.5 \%$ will be used. Changes in sulphur-containing emissions and $\mathrm{CO}_{2}$ and water emissions are in correspondence with the fuel composition.

The effect of the use of alternative fuels on contrail and aircraft induced cirrus is very uncertain ${ }^{2}$. It is assumed that the sulphur contents of the fuel as well as the soot emissions influence the formation of contrails significantly by providing condensation nuclei ${ }^{8,9}$. Thus, the expectation would be that synthetic fuels, with low to zero sulphur content and soot emissions, will reduce the amount of contrails and aircraft induced cirrus. On the other hand, the higher $\mathrm{h} / \mathrm{c}$ ratio of these fuels lead to an increased water emission which, in turn, will increase the formation of contrails. Furthermore, the optical properties of the contrails and cirrus may change with the changed emissions. The fewer soot particles emitted by an aircraft using synthetic fuel combined with the increased water emissions can result in fewer, possibly bigger droplets in the contrail. Furthermore, in the absence of more condensation nuclei, homogeneous condensation may also play a bigger role and create more droplets or ice crystals that consist only of water. Because of these uncertainties, it is decided to leave contrails and aircraft induced cirrus constant for different fuels.

\section{Radiative forcing modelling}

The radiative forcing of the direct and indirect emissions is calculated using the lifetime and sensitivity function of Ref. 10. The lifetime gives a measure of how long an emitted gas will remain in the atmosphere. The sensitivity 
function indicates the radiative forcing caused by the emission of 1 Dobson Unit, which equals a $0.01 \mathrm{~mm}$ thick column of emitted gas at sea level. This Dobson Unit can be derived from the molar mass of the emitted gas using the molar volume of air at sea level conditions and the area of the Northern hemisphere which is used as reference area. Both the lifetime and the sensitivity function are usually a function of altitude. No fixed time window is used for the calculation of the total radiative forcing caused by the emissions. Instead, time is kept as a variable in order to find the effects of the emissions over time. This means that the following integral is evaluated at different points in time ${ }^{10}$ :

$$
E_{i}=\int_{0}^{T} \Delta Y_{i}(h) \cdot S_{i}(h) \cdot e^{-t / \tau_{i}} d t
$$

Where $E_{i}$ is the warming effect of a gas with index $i, \Delta Y_{i}$ is the emitted amount of gas with index $i$ in Dobson Units as a function of altitude, $S_{\mathrm{i}}$ is the sensitivity function and $\tau_{\mathrm{i}}$ is the lifetime of gas with index $i$.

The radiative forcing caused by the emission of carbon dioxide is governed by the long lifetime of $\mathrm{CO}_{2}$ in the atmosphere. With a lifetime of 150 years $^{10}$ the gaseous emission has the chance to spread throughout the atmosphere. Thus, the effect of the emission of $\mathrm{CO}_{2}$ is independent of the altitude and a constant lifetime and sensitivity function of 150 years and $1.947 * 10^{-5} \mathrm{~W} / \mathrm{m}^{2} / \mathrm{DU}$, respectively, are used ${ }^{10}$.

Contrary to $\mathrm{CO}_{2}$ emissions, the effect of water emissions is dependent on altitude. At altitudes below, on average, $10 \mathrm{~km}$ water emissions mix with the normal water cycle in the atmosphere and it has a short lifetime. At higher altitude, however, the stability of the air in the stratosphere results in a much longer lifetime and radiative forcing effects. The lifetimes and severity factors are presented in Ref. 10. The effects of water emissions on contrail and cirrus formation are dealt with separately.

$\mathrm{NO}_{\mathrm{x}}$ emissions do not cause radiative forcing directly. Instead, it causes the creation of ozone $\left(\mathrm{O}_{3}\right)$ and destruction of methane $\left(\mathrm{CH}_{4}\right)$, both greenhouse gases. In this case, the emitted amount of gas, $\Delta \mathrm{Y}_{\mathrm{i}}$, is replaced by a production function. This production function determines the amount of $\mathrm{O}_{3}$ and $\mathrm{CH}_{4}$ created or destroyed by the emitted $\mathrm{NO}_{\mathrm{x}}$ as a function of time and altitude ${ }^{10}$. The maximum lifetime of $\mathrm{NO}_{\mathrm{x}}$ is in the order of days ${ }^{11}$, much smaller than the time horizons used in this study. Therefore, it can be assumed that the ozone and methane is produced instantly after emission without effect on the results.

Ozone has a lifetime of weeks at low altitude to months at high altitude. This is too short to fully mix the gas in the atmosphere and therefore an altitude variable sensitivity function is used. Methane on the other hand has a lifetime of up to nine years, which provides time for mixing. Therefore a constant sensitivity function of $5.362 * 10^{-4}$ $\mathrm{W} / \mathrm{m}^{2} / \mathrm{DU}$ can be used for methane.

Sulphate aerosols have a negative effect on radiative forcing. Ref. 2 assumed a radiative forcing of $-215 \mathrm{~W} / \mathrm{g}$ sulphate aerosol, independent of the altitude of emission as this is a direct albedo effect. With a lifetime of one week $^{12}$ and the reference area it is possible to use equation (1) to calculate the integrated radiative forcing (IRF) over time.

The direct effect of soot or black carbon is calculated in the same manner as sulphate aerosol. In this case, the positive radiative forcing of black carbon is $3000 \mathrm{~W} / \mathrm{g}$ soot at higher altitude where the soot is emitted above the clouds $^{2}$. The same lifetime as sulphate aerosol is assumed for black carbon particles.

The radiative forcing of contrails and aircraft induced cirrus is very uncertain ${ }^{2}$. Next to the unknown effect of aircraft emissions on contrail formation, the radiative forcing itself depends on the optical properties of the ice particles in the contrails as well as the thickness of the clouds. In this paper, results are presented for a narrow-body aircraft. The temperature change for a 100 year time horizon due to contrail and cirrus radiative forcing for this category aircraft is found on a basis of flight distance ${ }^{13}$. This temperature change can be compared with the temperature change due to one $\mathrm{kg}$ of $\mathrm{CO}_{2}$ emissions presented in the same research. Evaluation of equation (1) for one $\mathrm{kg}$ of $\mathrm{CO}_{2}$ and a time horizon equal to 100 years results in an IRF for this emission. Application of equation (1) in reverse leads to the sensitivity factor for contrails and cirrus at a specific altitude. The lifetime of a persistent contrail is in the order of hours, on average we assume six hours; while aircraft induced cirrus is estimated to last one day. The chosen lifetimes do not influence the results as the lifetimes cancel out by the use of equation (1) for the integrated radiative forcing and in reverse for the determination of the sensitivity factor. The sensitivity factor for one unit of flight length is found to be $1.65 * 10^{-8} \mathrm{~W} / \mathrm{m}^{2} / \mathrm{km}$ for contrails and $1.24 * 10^{-8} \mathrm{~W} / \mathrm{m}^{2} / \mathrm{km}$. This value is determined for an average fleet wide altitude by Ref. 13. If it is assumed that the average altitude used is $11 \mathrm{~km}$, the forcing factors for different altitudes presented by Ref. 13 provide the sensitivity function as a variable with altitude. 


\section{Results}

A single flight of an Airbus A320 size aircraft is analysed using the radiative forcing calculations. A typical continental flight of $1500 \mathrm{~km}$ with a payload of $15,000 \mathrm{~kg}$ is used. For this flight the integrated radiative forcing (IRF) is calculated for different altitudes and fuels. First of all, the effect of the different emissions for a flight at $11 \mathrm{~km}$ altitude using Jet A-1 is shown in figure 1. Under the current assumptions it is seen that the effects of contrails and aviation induced cirrus are the largest contributor to the total IRF. This stresses the importance of the knowledge of contrails and aviation induced cirrus and their influence on global warming. The contribution of contrails and cirrus is slightly larger than the IRF of $\mathrm{CO}_{2}$. Ozone and water form the other large contributions to the total IRF while soot, sulphate and methane are of minor importance.

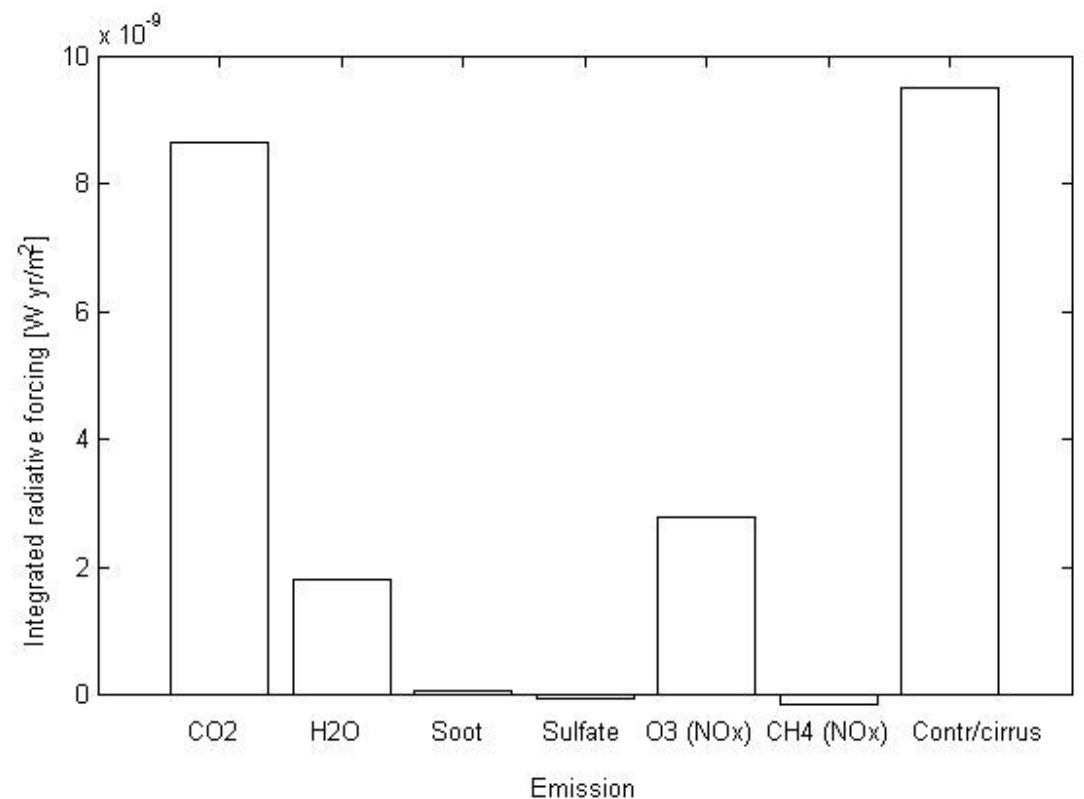

Figure 1. Integrated radiative forcing per emission, cruise altitude of $11 \mathrm{~km}$ and Jet A-1 fuel

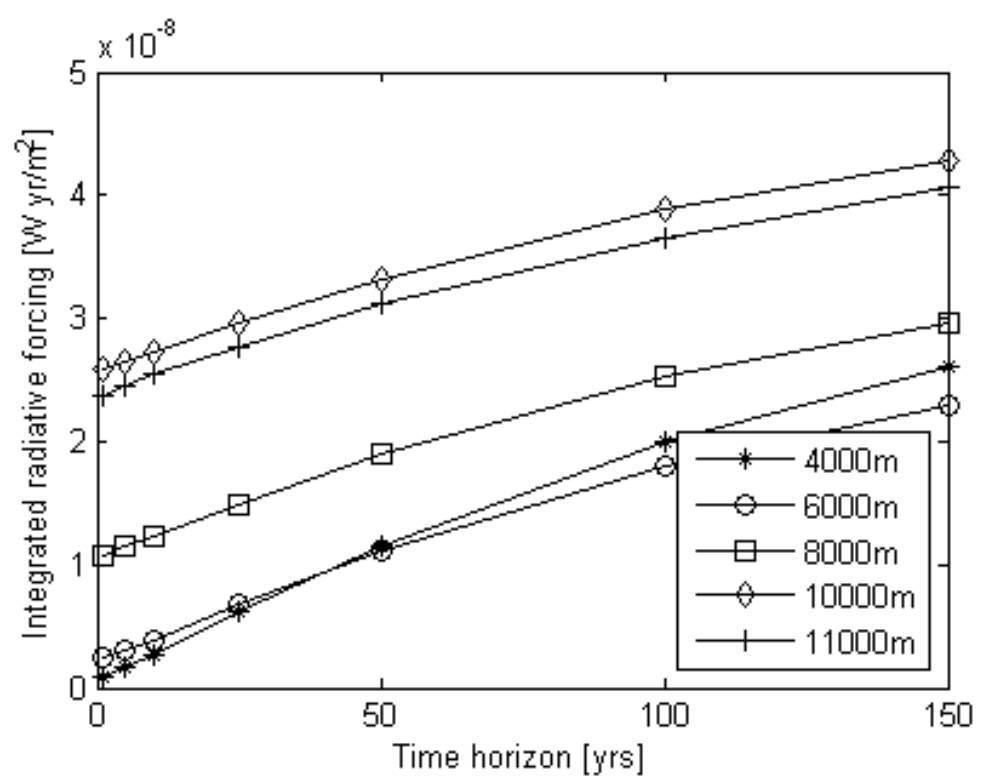

Figure 2. Integrated radiative forcing with variable time horizon and altitude, Jet A-1 fuel
Figure 2 shows the IRF for the given flight for different altitudes and a variable time horizon. The first point of each altitude line is for a time horizon of 1 year. This point is mainly composed of the contributions of the emissions with a short lifetime, most importantly ozone, water and contrails and cirrus. Since only ozone has an effect below $7 \mathrm{~km}$ altitude, the difference between a $4 \mathrm{~km}$ cruise altitude and a $6 \mathrm{~km}$ cruise altitude is determined by the production and sensitivity of ozone. This results in a slightly higher IRF for the $6 \mathrm{~km}$ cruise altitude. At higher altitudes the water emissions and contrails govern the IRF at the 1 year time horizon. This results in an increasing IRF with altitude up to $10 \mathrm{~km}$ cruise altitude. Above this altitude, contrails have a lower sensitivity function and IRF starts decreasing.

For all altitudes the IRF increases with the time horizon, with a tendency to level off at higher time horizons. The lines are steeper with decreasing altitude, which is a result of the larger amount of $\mathrm{CO}_{2}$ emitted when flying at a lower altitude. The curve for $4 \mathrm{~km}$ cruise altitude is steeper than that of a $6 \mathrm{~km}$ cruise altitude. This results in the IRF of $4 \mathrm{~km}$ cruise altitude raises above that of $6 \mathrm{~km}$ after about 40 years. For longer time horizons it will even raise above the $8 \mathrm{~km}$ cruise altitude curve. The other lines may only cross at very long time horizons and consequently, for a time horizon of 150 years a cruise altitude of $6 \mathrm{~km}$ has the lowest IRF. 
If the occurrence of contrails and aviation induced cirrus is omitted, the results are very different as is shown in figure 3. Such an omission might be considered reasonable if contrails could be avoided. However, such technology is not fully developed yet ${ }^{14}$. In figure 3 it is seen that the IRF for the low altitudes is equal to that in figure 2. The higher cruise altitudes show, as could be expected from figure 1, a much lower IRF. This places the IRF of the higher altitudes very close to those of the lower altitudes. For clarity of figure 3 , the $10 \mathrm{~km}$ cruise altitude is left out while the $11 \mathrm{~km}$ cruise altitude is dashed. As in figure 2, the IRF is determined by the short lived emissions at short time horizons while the increase in IRF depends on the $\mathrm{CO}_{2}$ emissions of the flight. In this case, the $6 \mathrm{~km}$ cruise altitude again results in the lowest IRF after 150 years. However, the lines indicate that if the time horizon would be increased after 150 years, the lowest IRF will be reached by the $11 \mathrm{~km}$ cruise altitude. The $4 \mathrm{~km}$ cruise altitude has

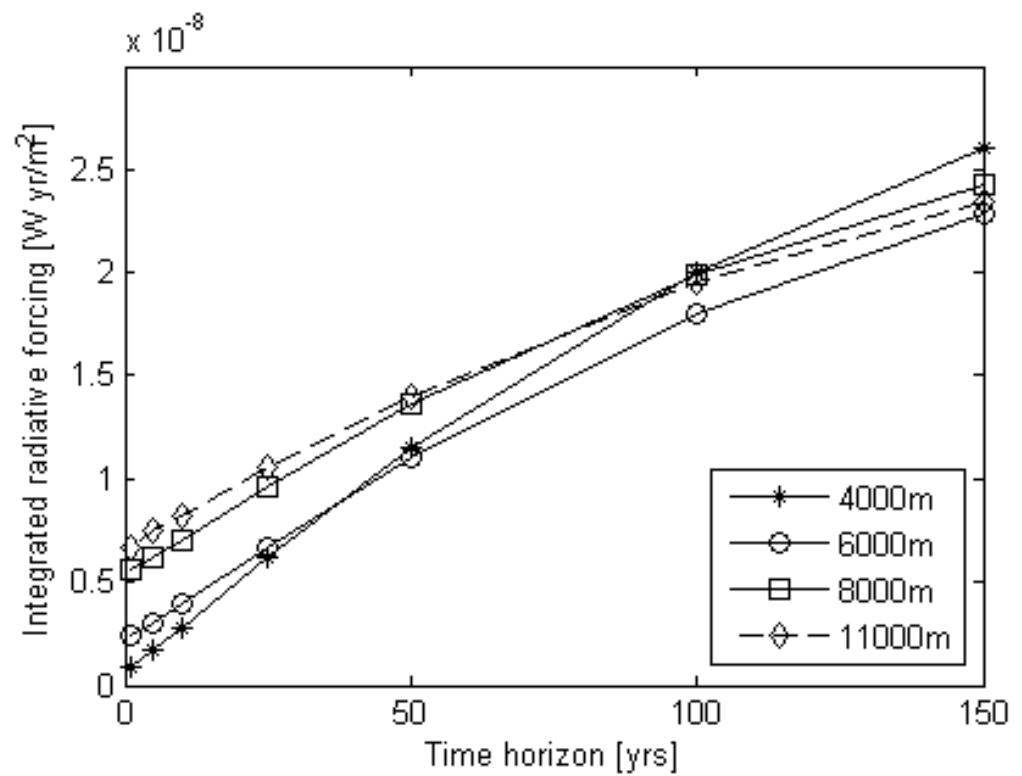

Figure 3. Integrated radiative forcing with variable time horizon and altitude, Jet A-1 fuel, without contrails the highest IRF after 100 years.

In figure 4 a comparison is made for the IRF of three different fuels used in the flight, assuming no contrails. The $11 \mathrm{~km}$ cruise altitude line from figure 3 is used for Jet A-1 while the IRF for a Gas-to-Liquid (GTL) synthetic kerosene is plotted next to it. The lower $\mathrm{CO}_{2}$ and $\mathrm{NO}_{\mathrm{x}}$ emissions of GTL result in a somewhat lower IRF for GTL

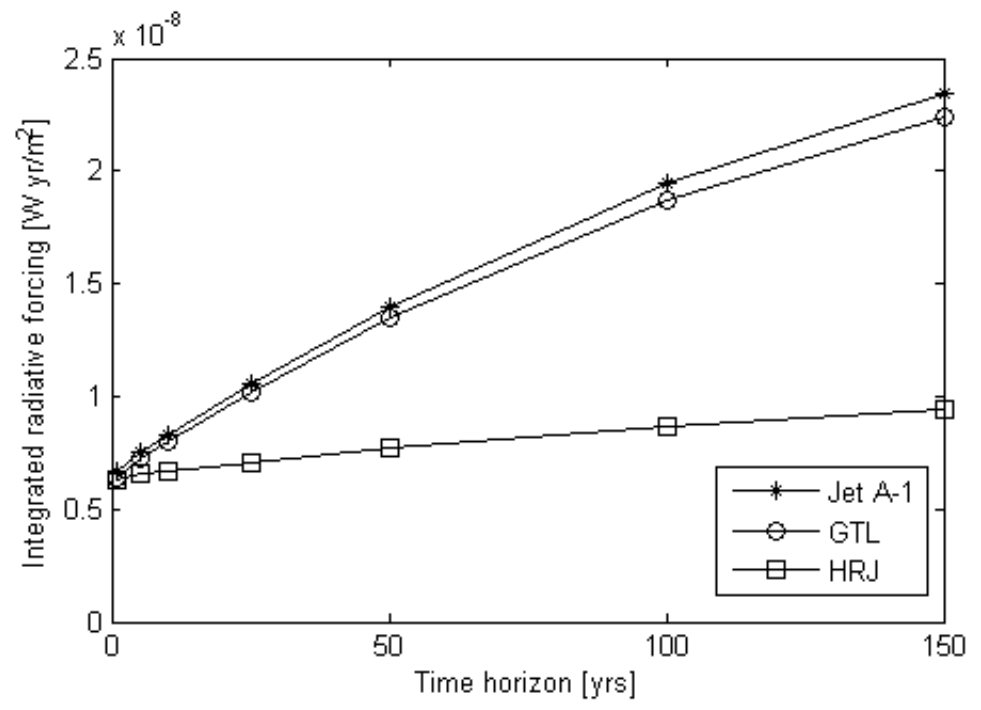

Figure 4. Integrated radiative forcing for different fuels, $11 \mathrm{~km}$ cruise altitude, without contrails than for Jet A-1, both at short and long time horizons. It has to be noted that this does not include possible emissions during production of GTL. For the IRF of Hydrotreated Renewable Jet fuel (HRJ) the same emissions as for GTL are used, with the assumption that $80 \%$ of the $\mathrm{CO}_{2}$ emitted was absorbed by the biomass used for producing the HRJ. Because of the long lifetime of $\mathrm{CO}_{2}$ this can be seen as an $80 \%$ reduction in $\mathrm{CO}_{2}$ emissions during flight. For a very short time horizon this means that the IRF of GTL and HRJ are nearly the same. However, due to the $\mathrm{CO}_{2}$ emissions the IRF for the use of GTL rises quickly while the IRF for the use of HRJ increases much slower. This results in an IRF for HRJ less than half the IRF for GTL and Jet A1 after 150 years. 


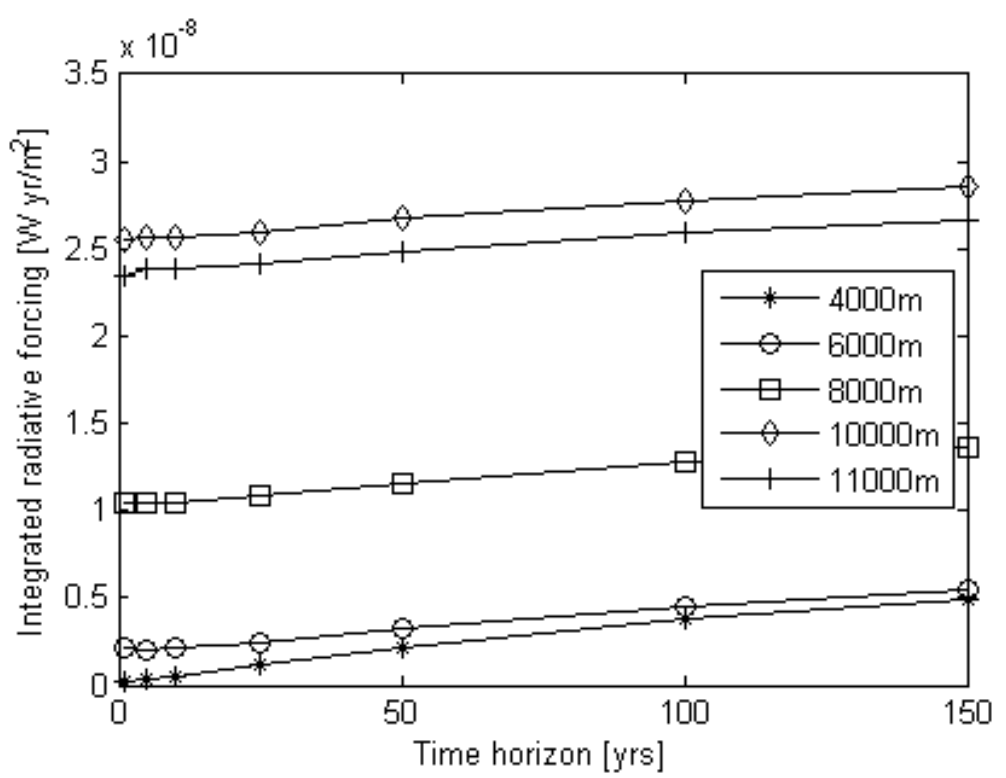

Figure 5. Integrated radiative forcing with variable time horizon and altitude, HRJ fuel
The IRF for flights at different cruise altitudes using HRJ, with $80 \% \mathrm{CO}_{2}$ emission reduction, is depicted in figure 5 . Contrails and aviation induced cirrus are included in this figure. For low cruise altitudes, the IRF is determined by the emissions of $\mathrm{NO}_{\mathrm{x}}$ at short time horizons and by the $\mathrm{CO}_{2}$ emissions at longer time horizon. As $\mathrm{NO}_{\mathrm{x}}$ emissions have low impact at $4 \mathrm{~km}$ altitude, the IRF of this altitude is nearly zero at the start. The higher $\mathrm{CO}_{2}$ emissions for a flight at this low altitude, however, increase the IRF in the long term. Therefore, it will surpass the IRF for the $6 \mathrm{~km}$ cruise altitude. At high altitudes the same trend is visible as for Jet A-1 for short time horizons in figure 2. The effect of contrails and aviation induced cirrus is the

highest at $10 \mathrm{~km}$ altitude and reduces for higher altitudes. Consequently, the cruise altitude of $10 \mathrm{~km}$ results in the highest IRF. The reduced $\mathrm{CO}_{2}$ emissions result in a relatively small increase in IRF over time and the total IRF after 150 years is still mainly determined by the contrails and cirrus.

When the occurrence of contrails and aviation induced cirrus is omitted again, this results in the IRF shown in figure 6. As in the case of Jet A-1, the IRF for low altitudes is unchanged compared to figure 5 and the lowest IRF for the very long term is reached for the $6 \mathrm{~km}$ cruise altitude. At short time horizons, the IRF is determined by the short lived emissions again and the high effects of NOx and water emissions at higher altitudes result in an increasing IRF with altitude. The IRF for 10 and $11 \mathrm{~km}$ cruise altitude are almost equal for all time horizons. With the exception of the IRF at 1 year, the IRF for the $11 \mathrm{~km}$ cruise altitude is slightly higher than the IRF for $10 \mathrm{~km}$ cruise altitude until the time horizons of around 100 years. The effect of the higher fuel consumption and slightly increased $\mathrm{CO}_{2}$ emissions at $10 \mathrm{~km}$ altitude increases the IRF for this altitude past the IRF for $11 \mathrm{~km}$ cruise altitude.

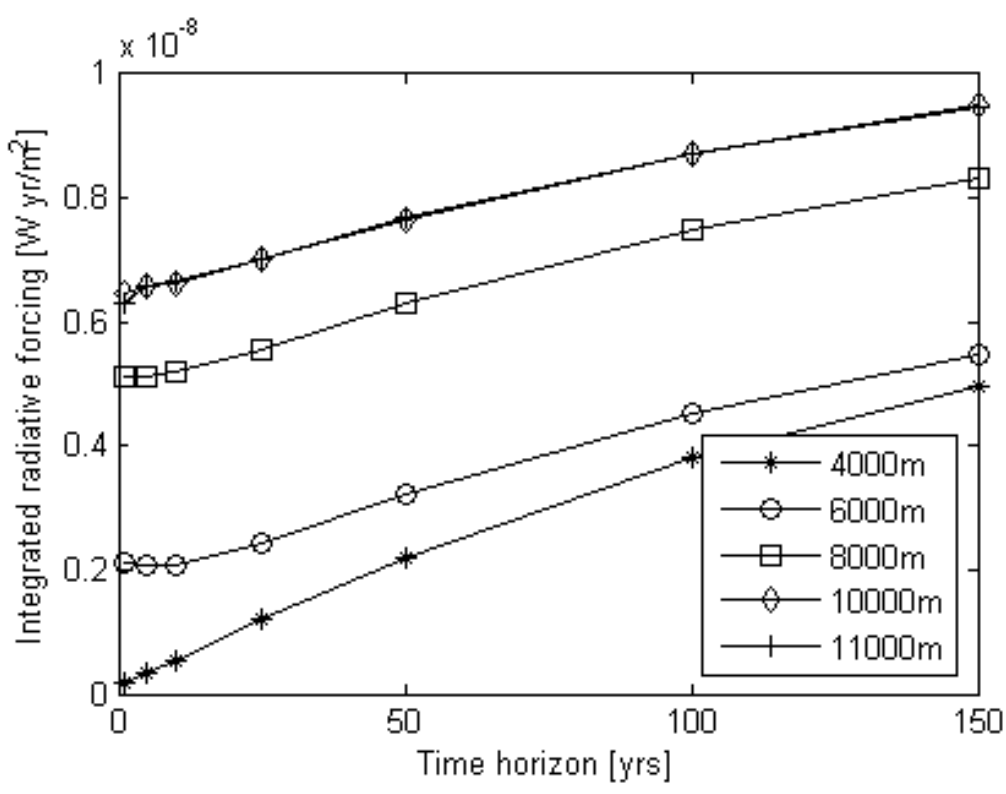

Figure 6. Integrated radiative forcing with variable time horizon and altitude, HRJ fuel, without contrails

\section{Conclusions}

A combination of an aircraft performance model and emission calculations provided the basic data needed to calculate the integrated radiative forcing caused by complete flights. With the used sensitivity functions and lifetimes of the different emissions, it is found that contrails and aviation induced cirrus have the largest influence on 
radiative forcing caused by aircraft. This stresses the importance of research and understanding of the production and radiative forcing of contrails and cirrus as these are very uncertain.

When the effect of cruise altitude on an aircraft is analysed, it is found that the lowest integrated radiative forcing (IRF) after 150 years is reached for a $6 \mathrm{~km}$ cruise altitude. The lower fuel consumption at higher cruise altitude is counteracted by the increased radiative forcing from contrails and cirrus and the highest IRF is reached for a cruise altitude of $10 \mathrm{~km}$. When the contrails and cirrus are omitted, the highest IRF is reached for a cruise altitude of $4 \mathrm{~km}$ while the lowest IRF is found for $6 \mathrm{~km}$ at a time horizon of 150 years. At a longer time horizon, the cruise altitude of $11 \mathrm{~km}$ will result in the lowest IRF.

The use of hydrotreated renewable jet (HRJ), for which it is assumed that $80 \%$ of the carbon comes from renewable sources, again results in the lowest IRF for a $6 \mathrm{~km}$ cruise altitude. Due to the contrails and cirrus a cruise altitude of $10 \mathrm{~km}$ leads to the highest IRF. If contrails and cirrus are avoided, still the lowest IRF is found for a cruise altitude of $6 \mathrm{~km}$ and the highest IRF is found for a cruise altitude of $10 \mathrm{~km}$.

\section{References}

${ }^{1}$ Snijders, T.A., Melkert, and J.A., Bogers, P.F., “Performance Effects from Alternative Jet Fuels”, DGLR German Aerospace Conference, DLRK 2009-1287, Aachen, Germany, 2009.

${ }^{2}$ Penner, J.E., Lister, D.H., Griggs, D.J., Dokken, D.J., and McFarland, M., Aviation and the global atmosphere, Cambridge University Press, United Kingdom, 1999.

${ }^{3}$ Baughcum, S. L., Tritz, T.G., Henderson, S.C., and Pickett, D.C., "Scheduled civil aircraft emissions inventories for $1992:$ database development and analysis," NASA CR-4700, 1996.

${ }^{4}$ Döpelheuer, A., and Lecht, M., "Influence of engine performance on emission characteristics”, Symposium on Gas Turbine Engine Combustion, Emissions and Alternative Fuels, MP-14, RTO, Lisbon, Portugal, 1998, pp. 20-1-20-12.

${ }^{5}$ Srinivasan, A., Ellis, B., Crittenden, J.F., Lear, W.E., Rotavera, B., and Petersen, E.L., "Fischer-Tropsch Fuel Characterization via Microturbine Testing and Fundamental Combustion Measurements”, Proceedings of ASME Turbo Expo 2008: Power for Land, Sea and Air, GT2008-51447, Berlin, Germany, 2008.

${ }^{6}$ Rahmes, T.F. et al., "Sustainable Bio-Derived Synthetic Paraffinic Kerosene (Bio-SPK) Jet Fuel Flights and Engine Test Program Results”, $9^{\text {th }}$ AIAA Aviation Technology, Integration and Operations Conference, AIAA 2009-7002, Hilton Head, SC, USA, 2009.

${ }^{7}$ Corporan, E., DeWitt, M.J., Klingshirn, C.D., Striebich, R., and Cheng, M.-D., "Emissions Characteristics of Military Helicopter Engines with JP-8 and Fischer-Tropsch Fuels,” Journal of Propulsion and Power, Vol. 26, No. 2, 2010, pp. 317-324.

${ }^{8}$ Kärcher, B., "On the potential importance of sulfur-induced activation of soot particles in nascent jet aircraft exhaust plumes”, Atmospheric Research, Vol. 46, 1998, pp. 293-305.

${ }^{9} \mathrm{Yu}, \mathrm{F}$, and Turco, R.P., "Contrail formation and impacts on aerosol properties in aircraft plumes: Effects of fuel sulfur content”, Geophysical Research Letters, Vol. 25, No. 3, 1998, pp. 313-316.

${ }^{10}$ Svensson, F., Hasselrot, A., and Moldanova, J., "Reduced environmental impact by lowered cruise altitude for liquid hydrogen-fuelled aircraft”, Aerospace Science and Technology, No. 8, 2004, pp. 307-320.

${ }^{11}$ Ehhalt, D.H., Rohrer, F., and Wahner, A., "Sources and distribution of $\mathrm{NO}_{\mathrm{x}}$ in the upper troposphere at northern midlatitudes”, Berichte des Forschungszentrums Jülich 2488, 1991.

${ }^{12}$ Andronova, N., and Schlesinger, M., "Importance of sulfate aerosol in evaluating the relative contributions of regional emissions to the historical global temperature range,” Mitigation and Adaptation Strategies for Global Change, No. 9, 2004, pp. 383-390.

${ }^{13}$ Schwartz, E., and Kroo, I.M., “Aircraft Design: Trading Cost and Climate Impact”, $47^{\text {th }}$ AIAA Aerospace Sciences Meeting, AIAA 2009-1261, Orlando, FL, USA, 2009.

${ }^{14}$ Noppel, F., and Singh, R., “Overview of Contrail and Cirrus Cloud Avoidance Technology”, Journal of Aircraft, Vol. 44, No. 5, 2007, pp. 1721-1726. 